\title{
Validation of the Korean Version of the Abbreviated Profile of Hearing Aid Benefit
}

\author{
Hyun Jung Lim ${ }^{1}$, Moo Kyun Park ${ }^{1,2}$, Yang-Sun Cho ${ }^{2,3}$, Gyu Cheol Han ${ }^{2,4}$, \\ Jin-Woong Choi ${ }^{2,5}$, Yong-Hwi An ${ }^{2,6}$, Bong Jik Kim ${ }^{2,7}$, and Byung Yoon Choi ${ }^{2,8}$ \\ ${ }^{I}$ Department of Otorhinolaryngology-Head and Neck Surgery, Seoul National University Hospital, \\ Seoul National University College of Medicine, Seoul; and ${ }^{2}$ Questionnaire Translation Committee the Korean Audiological Society, \\ Seoul; and ${ }^{3}$ Department of Otorhinolaryngology-Head and Neck Surgery, Samsung Medical Center, \\ Sungkyunkwan University School of Medicine, Seoul; and ${ }^{4}$ Department of Otorhinolaryngology-Head and Neck Surgery, \\ Gil Medical Center, Gachon University of Medicine \& Science, Graduate School of Medicine, Incheon; and \\ ${ }^{5}$ Department of Otolaryngology-Head and Neck Surgery, Chungnam National University Hospital, \\ Chungnam National University College of Medicine, Daejeon; and ${ }^{6}$ Department of Otorhinolaryngology-Head and Neck Surgery, \\ Eulji Hospital, Eulji University College of Medicine, Seoul; and ${ }^{7}$ Department of Otorhinolaryngology-Head and Neck Surgery, \\ Dankook University Hospital, Dankook University College of Medicine, Cheonan; and ${ }^{8}$ Department of Otorhinolaryngology-Head and \\ Neck Surgery, Seoul National University Bundang Hospital, Seoul National University College of Medicine, Seongnam, Korea
}

\section{한국어판 Abbreviated Profile of Hearing Aid Benefit의 타당도 및 신뢰도 검증}

임현정 ${ }^{1}$ 박무균 ${ }^{1,2} \cdot$ 조양선 ${ }^{2,3}$ - 한규철,4 최진웅 $^{2,5} \cdot$ 안용휘 ${ }^{2,6} \cdot$ 김봉직 ${ }^{2,7} \cdot$ 최병윤 ${ }^{2,8}$

서울대학교 의과대학 서울대학교병원 이비인후과학교실, ${ }^{1}$ 대한청각학회 설문지 번역위원회, ${ }^{2}$

성균관대학교 의과대학 삼성서울병원 이비인후과학교실, ${ }^{3}$ 가천대학교 의과대학 길병원 이비인후과학교실, ${ }^{4}$

충남대학교 의과대학 충남대학교병원 이비인후과학교실, ${ }^{5}$ 을지대학교 의과대학 을지병원 이비인후과학교실, ${ }^{6}$

단국대학교 의과대학 단국대학교병원 이비인후과학교실, ${ }^{7}$ 서울대학교 의과대학 분당서울대학교병원 이비인후과학교실

\author{
Received October 30, 2016 \\ Revised December 31, 2016 \\ Accepted January 4, 2017 \\ Address for correspondence \\ Byung Yoon Choi, MD \\ Department of Otorhinolaryngology, \\ Seoul National University \\ Bundang Hospital, \\ Seoul National University \\ College of Medicine, \\ 82 Gumi-ro 173beon-gil, \\ Bundang-gu, Seongnam \\ 13620, Korea \\ Tel $+82-31-787-7406$ \\ Fax +82-31-787-4057 \\ E-mail choiby2010@gmail.com
}

Background and Objectives The quantification of hearing aid benefit is important in hearing aid fitting. The abbreviated profile of hearing aid benefit (APHAB) is a useful tool for measuring the benefit of using hearing aids. In this study, we developed a Korean version of APHAB (K-APHAB) and determined its validity and reliability.

Subjects and Method An expert panel translated the original version of APHAB into Korean language. Two bilingual translators back-translated the first translated version into English and it was compared with the original version. After cognitive debriefing, the translation of APHAB into the Korean version was completed. One hundred ninety-seven subjects using hearing aids participated in this study and completed K-APHAB. Reliability was assessed using Cronbach's alpha coefficient, and validity was evaluated by factor analysis and criterion validity. Results K-APHAB had a good internal consistency $(\alpha=0.80)$. Confirmatory factor analysis showed that K-APHAB is comprised of four subsections, namely 'communication in daily life', 'aversiveness', communication in 'background noise' or 'reverberation'.

Conclusion The K-APHAB is a useful tool for evaluating the benefit of hearing aids in Korean hearing-impaired individuals.

Korean J Otorhinolaryngol-Head Neck Surg 2017;60(4):164-73

Key Words Hearing aid · Questionnaire · Reliability · Translation · Validity.

This is an Open Access article distributed under the terms of the Creative Commons Attribution Non-Commercial License (http://creativecommons.org/licenses/by-nc/4.0) which permits unrestricted non-commercial use, distribution, and reproduction in any medium, provided the original work is properly cited. 


\section{서 론}

수술적 치료가 적합하지 않은 난청환자들에게 보청기는 효과적인 재활방법이며, 적절한 보청기 처방 및 조절을 위해 보청기 착용 전후의 이득을 평가하는 과정은 필수적이다. 청 각 검사는 보청기 착용으로 인한 청각학적 이득을 평가하지 만, 환자 본인이 실제적으로 느끼는 만족도를 충분히 반영하 지는 못한다. 이에 보청기 착용 이득에 대한 주관적인 증상을 객관화하고 정량화할 수 있는 도구의 개발은 성공적 보청기 사용을 위해 매우 중요하다.

이러한 배경하에서 외국에서는 많은 보청기 이득 측정 도구 들이 개발되어 활용되고 있다. 국내에서도 Yun 등이 이 abbreviated profile of hearing aid benefit(APHAB)를 이용하여 보 청기 사용 전후의 이득을 비교하였고, Lee 등른 atisfaction with amplification in daily life(SADL) 설문지를 이용하여 주 관적 만족도를 평가하였다. 하지만 이러한 도구들은 대부분 영어권 국가에서 만들어졌기 때문에 우리나라에서 이를 단 순 번역하여 활용하는 데에는 언어 및 문화적 제한이 있다. $\mathrm{Chu}$ 등근 타당도와 신뢰도 검정을 통한 International Outcome Inventory for Hearing Aids(IOI-HA)의 한국어판 설문 지를 제시하였지만, 그 외 대부분의 설문지의 경우 각 연구자 들이 개별로 번역하여 별도의 검증 절차 없이 사용하고 있다.

본 연구에서는 국내 보청기 착용 환자들의 임상 진료 및 연구에 표준화된 보청기 이득 평가도구를 제공하기 위하여, 신뢰도가 높아 국제적으로 널리 사용되고 있는 $\mathrm{APHAB}$ 를 국내 사정에 맞게끔 한국어로 번역하고 이 한국어판의 타당 도 및 신뢰도를 평가하였다.

\section{대상 및 방법}

\section{방 법}

\section{대상 설문지}

$\mathrm{APHAB}$ 는 총 4개의 세부 항목, 24 개 문항으로 구성되어 있 으며 각 문항은 7 개의 점수 척도로 평가한다. 총 4 개의 항목 은 ease of communication(EC), reverberation(RV), background noise $(\mathrm{BN})$, aversiveness(AV)이며, 각 세부 항목은 6 개의 문항으로 이루어져 있다(EC=문항 $4,10,12,14,15,23$; $\mathrm{RV}=$ 문항 $1,6,7,16,19,24 ; \mathrm{BN}=$ 문항 $2,5,9,11,18,21$; $\mathrm{AV}=$ 문항 $3,8,13,17,20,22)$. 각 문항에 대해서는 항상 (99\%), 거의 항상 $(87 \%)$, 대체로 $(75 \%)$, 절반 정도 $(50 \%)$, 가끔 (25\%), 드물게(12\%), 전혀 아니다(1\%)의 7개 점수 척도 중 하 나로 평가하여 \%로 표시하며, 보청기 착용 전과 후에 대해 각
각 답변하도록 되어 있다.

\section{번역 및 설문지 완성}

\section{$\mathrm{APHAB}$ 설문지 원본 획득}

교신저자가 전자우편으로 원저자인 Dr. Cox를 접촉하여 한국어판 번역에 대한 허가를 얻고 $\mathrm{APHAB}$ 의 원본을 제공 받았다.

순 번역(Forward translation)

대한청각학회 설문지 번역위원회에서 영어판 $\mathrm{APHAB}$ 의 순 번역 지침을 마련한 후, 2 인의 기획위원이 한글로 각자 번역하 였다.

\section{절충(Reconciliation)}

번역위원회에서 두 번역본을 검토하여 한국어 절충 번역본 을 만들었다.

역 번역(Backward translation)

한국어 절충 번역본을 양국 언어에 능통한 제 3 의 번역자가 역 번역하였다. 그 후 위원회에서 설문지 원본과 역 번역본을 비교 검토하였고, 원본의 항목 개념과 역 번역한 문장의 항목 개념이 포함되었을 경우 번역이 제대로 된 것으로 평가하였으 며, 포함되지 않은 경우에는 재검토를 시행하였다. 새로 만들어 진 문장이 수용되면 이 과정은 완성되는 것으로 결정하였다.

\section{인지적 확인(Cognitive debriefing)}

서울대병원 이비인후과 외래에서 보청기를 착용하는 환자 10 명에게 독립적으로 역 번역까지 완성된 설문지를 제공하 여 설문 응답의 소요시간을 측정하고, 이후 원래 질문의 개념 을 잘못 이해하고 있거나 이해가 힘든 부분, 질문 내용이 애매 하거나 매끄럽지 않은 부분에 대한 의견을 받고 이를 정리하 였다.

감 수

완성된 역 번역본의 국어 오류의 여부를 확인하기 위해 국 어교육평가원에 감수를 의뢰하였다.

최종 교정

국어교육평가원의 감수 내용을 바탕으로 최종 검증을 거쳐 한국어판을 완성하였다. 
타당도 및 신뢰도 검사

대상자 선정

가천의대 길병원, 가톨릭의대 서울성모병원, 고려대학교 부 속 구로병원, 단국대학교병원, 동아대학교병원, 서울대학교병 원, 서울대학교 부속 분당병원, 성균관의대 삼성서울병원, 연세 대학교 세브란스병원, 울산대학교 서울아산병원, 을지대학교 부속 노원병원, 전남대학교병원, 충남대학교병원 및 한양대 학교 부속 구리병원 총 14 개 병원(가나다 순)에서 난청으로 보 청기를 착용하고 있는 환자를 대상으로 하였으며, 연구에 참 여한 병원은 모두 연구 전 각 병원의 임상연구윤리위원회(IRB No. 1409-092-610)의 심의를 받았다.

신뢰도 및 타당도 조사

연구에 참여한 병원으로 $\mathrm{APHAB}$ 최종 한국어판 인쇄물 과 설문작성을 위한 해설서를 우편으로 배포하였다. 환자들 에게 연구 참여에 대한 동의를 구한 후 설문지 작성 작업을 시행하였고, 환자 본인이 설문지 작성하는 것을 원칙으로 하 되 이해가 되지 않는 문항에 대해서는 보호자와 같이 상의하 여 작성하도록 하였다.

$\mathrm{K}-\mathrm{APHAB}$ score 및 보청기 착용 이득

Korean version of $\mathrm{APHAB}(\mathrm{K}-\mathrm{APHAB})$ 의 각 문항은 항상 (99\%), 거의 항상 $(87 \%)$, 대체로 $(75 \%)$, 절반 정도 $(50 \%)$, 가끔 (25\%), 드물게(12\%), 전혀 아니다(1\%)의 7개 Point Scale을 이용하여 보청기 착용 전과 착용 후의 장해 정도를 각각 점 수화하였다. 본 설문지는 긍정형 질문과 일부 부정형 질문 (항목 $1,9,11,16,19,21$ )이 섞여 있는 설문지로, 보청기 착 용 이득을 구할 때 긍정형 질문의 경우 보청기 착용 전 점수 에서 보청기 착용 후 점수를 뺀 값으로 계산하였고, 부정형 질문의 경우 보청기 착용 후 점수에서 보청기 착용 전 점수 를 뺀 값으로 구하였다. 각 문항의 보청기 착용 이득을 구한 이후, 4가지 세부 항목 $\mathrm{EC}, \mathrm{RV}, \mathrm{BN}, \mathrm{AV}$ 에 해당하는 각 6 문 항들의 평균을 구하였다.

\section{결 과}

\section{인지적 확인(Cognitive debriefing)}

순 번역 및 역 번역까지 마친 K-APHAB의 평균 소요시간 은 11분(10 13분)으로, $\mathrm{APHAB}$ 원저 소요시간 10 분과 큰 차 이를 보이지 않았지만, $1,2,3,8,9,10,14,21,23$ 번 문항들 의 질문이 다소 이해하기 힘들었다는 의견이 있었다. 이에 좀 더 매끄러운 문장으로 수정하는 과정을 거쳤고, 그중 3 번 문
항을 예로 들면 '화재 경보 또는 비상벨과 같은 예기치 못한 소리가 불편합니다'에서 '화재 경보기나 또는 자명종과 같은 갑작스런 소리가 불쾌합니다'로 수정되었다.

\section{연구 대상자의 임상적 특징}

최종 한국어판 $\mathrm{APHAB}(\mathrm{K}-\mathrm{APHAB})$ 를 제작하였고(Appendix 1), 14 개 기관에서 총 197 명의 환자가 설문에 답하였 으며, 이 중 남자는 92 명, 여자는 105 명이었으며, 이들의 평균 연령은 남녀 각각 $62( \pm 19)$ 세, $68( \pm 15)$ 세였다. 청력은 $40 \mathrm{~dB}$ 이하의 경도 난청 14 명, 중도 난청 24 명, 중고도 난청 37 명, 고 도 난청 96명 그리고 심도 난청 26명이었다. 보청기 착용 경력 은 6주 미만 42명, 6주에서 1년 미만 55명, 1년 이상 10년 미만 78 명, 10 년 이상 18 명이었다(무응답 4명). 하루 동안 보청기 착 용을 전혀 하지 않는 사람이 7 명, 1 시간 미만 5 명, 1 시간 이상 4시간 미만 24명, 4시간 이상 8시간 미만 73명, 8시간 이상 16

Table 1. Clinical characteristics enrolled in the study

\begin{tabular}{|c|c|c|}
\hline Category & $n$ & $\%$ \\
\hline \multicolumn{3}{|l|}{ Gender } \\
\hline Male & 92 & 47 \\
\hline Female & 105 & 53 \\
\hline \multicolumn{3}{|l|}{ Age } \\
\hline$<40$ & 20 & 10 \\
\hline $40-49$ & 10 & 5 \\
\hline $50-59$ & 14 & 7 \\
\hline $60-69$ & 44 & 22 \\
\hline $70-79$ & 79 & 40 \\
\hline$\geq 80$ & 30 & 15 \\
\hline \multicolumn{3}{|c|}{$\begin{array}{l}\text { Pure-tone average in the } \\
\text { better ear ( } \mathrm{dB} \mathrm{HL})\end{array}$} \\
\hline$\leq 40$ & 14 & 7 \\
\hline $41-55$ & 24 & 12 \\
\hline $56-70$ & 37 & 19 \\
\hline $71-90$ & 96 & 49 \\
\hline$>90$ & 26 & 13 \\
\hline \multicolumn{3}{|l|}{ Hearing aid experience } \\
\hline$<6$ weeks & 42 & 21 \\
\hline 6 weeks-11 months & 55 & 28 \\
\hline $1-10$ years & 78 & 40 \\
\hline$\geq 10$ years & 18 & 9 \\
\hline Not reported & 4 & 2 \\
\hline \multicolumn{3}{|l|}{ Average daily use } \\
\hline None & 7 & 4 \\
\hline$<1$ hour & 5 & 3 \\
\hline $1-4$ hours & 24 & 12 \\
\hline $4-8$ hours & 73 & 37 \\
\hline $8-16$ hours & 83 & 42 \\
\hline Not reported & 5 & 3 \\
\hline
\end{tabular}


시간 미만이 83명이었다(무응답 5명)(Table 1).

\section{보청기 착용 이득}

문항별 $\mathrm{K}-\mathrm{APHAB}$ score, 보청기 이득 평균, 표준편차 그리 고 각 문항의 응답률을 구하였고(Appendix 2), K-APHAB 세부 항목 $\mathrm{EC}, \mathrm{BN}, \mathrm{RV}, \mathrm{AV}$ 의 보청기 착용 이득 평균은 각각 $24.8( \pm 30.7), 22.5( \pm 22.3), 23.5( \pm 24.4),-18.7( \pm 28.2)$ 이었으며, 보청기 사용 전후 순음청력검사상 이득의 평균은 $18.6( \pm 9.3)$ $\mathrm{dB}$ 이었다(Table 2).

\section{신뢰도}

K-APHAB의 내적 일치도는 Cronbach's alpha coefficient로 평가하였으며, 24문항에 대한 Cronbach's alpha 값은 0.8로 높 은 내적 일치도를 보였다. 4가지 세부 항목에 대한 Cronbach's alpha 값은 $\mathrm{EC}$ 는 $0.86, \mathrm{AV}$ 는 0.85 로 높았으나, $\mathrm{BN}$ 은 $0.58, \mathrm{RV}$ 는 0.65 로 다소 낮은 값을 보였다.

\section{타당도}

\section{구성개념 타당도}

요인 분석

K-APHAB의 Kaiser-Meyer-Olkin ratio는 0.82로 높게 나타나, 본 연구에 사용된 24 개의 문항이 요인 분석에 적절 한 표본임을 알 수 있었다. Varimax rotation을 이용하여 주 성분 분석을 시행하였으며, 1 이상의 eigenvalue를 갖는 5 개 의 요인이 추출되었으나, scree plot에서 3번째 요인 이후로 그래프의 기울기가 급격히 감소되어(Fig. 1), 본 연구에서는 $\mathrm{K}-\mathrm{APHAB}$ 를 설명할 요인을 3개로 결정하였다. 요인 수를 3 개로 설정하여 분석한 결과, 3 개의 요인에 의해 설명되는 비 율은 총 $58 \%$ 였으며, 각 요인의 설명력은 제 1 요인 $30 \%$, 제 2 요 인 $21 \%$, 제3요인 $7 \%$ 였고, 24문항 모두 각 문항과 요인 간의

Table 2. Means and SDs of hearing aid benefit for each subscale of K-APHAB and pure tone audiogram

\begin{tabular}{lcc}
\hline Category & Mean of hearing aid benefit & SD \\
\hline K-APHAB subscales & & \\
EC & 24.8 & 30.7 \\
BN & 22.5 & 22.3 \\
RV & 23.5 & 24.4 \\
AV & -18.7 & 28.2 \\
PTA (dB) & 18.6 & 9.3 \\
\hline
\end{tabular}

K-APHAB: Korean version of abbreviated profile of hearing aid benefit, EC: ease of communication, BN: background noise, RV: reverberation, AV: aversiveness, SD: standard deviation, PTA: pure tone audiometry
상관관계를 나타내는 적재량이 0.40 이상으로 유의성이 있었 다(Appendix 3).

\section{요인 명명}

3 가지 요인들의 명명을 위해 각 요인에 해당하는 문항을 분석한 결과, 제 1 요인에 해당하는 문항은 '강의나 수업 듣기', '집에서 가족과의 대화, '영화 또는 공연의 대사 청취', '차 안 에서 다른 사람들 간의 대화 중 라디오 청취', '여러 사람과 저 녁 식사 중 한 사람과의 대화, '사무실에서 질문을 받고 대답 하기', '친구 한 사람과 조용히 대화, '모임에서의 대화, '진찰 실에서 의사와의 대화, '교회 예배 내용 듣기', '조용한 방에서 일대일로 대화, '기계소음 속에서의 대화'의 12 문항으로, 일 상 생활 전반에 걸친 내용들이 포함되어 있어 제1요인을 '일 상 생활에서의 의사 소통'이라 명명하였다. 제 2 요인에는 '화 재 경보 또는 자명종 같은 갑작스러운 소리의 불쾌감', '교통 소음의 시끄러움, '샤워기 또는 변기 물 내리는 소리의 불쾌 감', '공사장 소음의 시끄러움, '소방차 사이렌 소리의 시끄러 움, '급정거 시 타이어 소리의 불쾌감’의 6 문항이 속해 있으 며, 모두 큰 소리에 대한 불쾌감에 관한 내용이므로 제2요인 을 ‘큰 소리에 대한 불쾌감'이라 명명하였다. 제3요인에는 '혼 잡한 식품 매장 계산 시 대화', '큰 방안에서 건너편 사람과의 대화, '극장 또는 공연장에서 주변의 속삭이는 소리 또는 바 스락거리는 소음이 있는 상황에서 대사 청취', '여러 사람들 과의 대화, '혼잡한 군중 속에서의 대화, '종교의식에서 설교 나 강의 청취'의 6 문항이 포함되어 있으며, 모두 소음 환경 또는 반향음에서의 의사 소통에 관련된 내용이므로 제 3 요인 을 '소음/반향음에서의 의사 소통'이라 명명하였다.

\section{준거 타당도}

$\mathrm{K}-\mathrm{APHAB}$ 의 준거 타당도는 보청기 사용 시 얻는 청각학적 이득과 $\mathrm{K}-\mathrm{APHAB}$ 설문을 통해 얻은 보청기 착용 이득의 상 관관계를 Spearman's correlation coefficient를 구하여 분

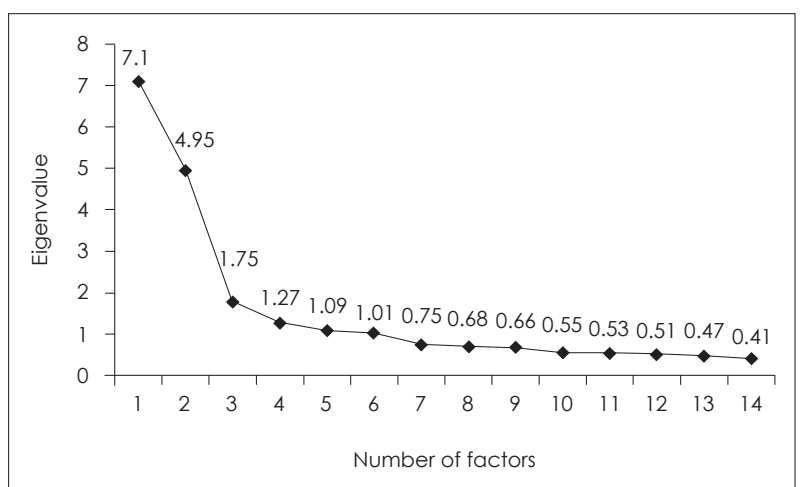

Fig. 1. Scree plot. 
석하였다. 세부 항목 $\mathrm{EC}, \mathrm{BN}, \mathrm{RV}, \mathrm{AV}$ 와 청각학적 이득 사이 의 Spearman's correlation coefficient는 각각 $0.11,0.08$, $0.11,-0.07$ 이었으며, 모두 의미 있는 상관관계는 보이지 않았 다 $(p>0.05)$. 하지만 각 문항별 보청기 착용 전과 착용 후의 $\mathrm{K}-\mathrm{APHAB}$ score는 모든 문항에서 통계적으로 유의한 차이 를 보였다 $(p<0.000)$ (Appendix 2).

\section{고 찰}

보청기 착용 전후 수행능력과 만족도를 평가하는 설문지에 는 보청기 착용 전후의 이득을 측정하는 Hearing Handicap Scale, ${ }^{4)}$ Hearing Aid Profile Inventory, ${ }^{5)}$ Hearing Handicap Inventory, ${ }^{6} \mathrm{APHAB}^{7)}$ 등이 있으며, 보청기의 주관적인 만족 도를 조사하는 설문지인 IOI-HA, ${ }^{8)} \mathrm{SADL}^{9)}$ 그리고 사용자의 다양한 인구사회학적 환경에 따른 만족도를 조사하는 Marke Trak Survey ${ }^{10}$ 가 있다. Cox와 Gilmore ${ }^{11)}$ 는 보청기 착용 환자의 경험에 대한 설문지인 profile of hearing aid performance (PHAP)를 개발하였고, 그 뒤 보청기 착용한 상태와 착용하 지 않은 상태를 모두 평가하는 profile of hearing aid benefit $(\mathrm{PHAB})^{12)}$ 를 개발하여 보청기 착용으로 인한 이득을 측정할 수 있게 되었다. 하지만 PHAP와 PHAB의 경우 임상에서 사 용하기에는 문항수가 많고 복잡하여, 임상에서 보다 쉽게 사용 할 수 있는 설문지의 개발이 필요하였다. 이에 Cox와 Alexan$\mathrm{der}^{7,13)}$ 는 $\mathrm{PHAB}$ 의 7개의 항목과 66개의 문항에서 신뢰도가 높은 4항목과 24문항을 선택한 $\mathrm{APHAB}$ 를 제시하게 되었다. 이로써 $\mathrm{APHAB}$ 는 검사하는데 약 10 분 정도의 짧은 시간이 소요되면서, 환자들이 특정 상황에서의 의사 소통에 있어 각 보청기의 장점과 단점을 더욱 잘 평가하게 되었을 뿐만 아니 라 보청기 착용 이득의 주관적인 요소를 기록할 수도 있게 되 었다. $\mathrm{APHAB}$ 는 보청기 착용 이득 평가가 필요한 실제 임상 환 경에서 활용가능하며, 여러 난청 그룹에서의 보청기들의 비교 평가하는 연구에도 사용될 수 있다.

$\mathrm{K}-\mathrm{APHAB}$ 의 작성 소요시간은 약 11 분으로 원저의 소요시 간과 큰 차이가 없었으며, $\mathrm{K}-\mathrm{APHAB}$ 역시 보청기 착용 이득 을 평가하는 데 임상에서 쉽게 이용할 수 있을 것으로 기대된 다. 그리고 세부 항목 $\mathrm{EC}, \mathrm{BN}, \mathrm{RV}$ 의 보청기 착용 이득 평균값 이 각각 $24.8,22.5,23.5$ 로 다양한 환경(조용한 환경, 소음 환 경, 반향음 환경)의 대화에서 보청기 착용 이득이 있음을 확인 하였고, 세부 항목 $\mathrm{AV}$ 의 경우 평균값이 -18.7로 큰소리에 대 한 혐오감은 오히려 보청기 착용 시 더 커짐을 확인할 수 있었 다(Table 2). 이는 이전 $\mathrm{APHAB}$ 관련 다른 연구 결과와도 부합 한다. ${ }^{7,14,15)}$

응답률의 경우 평균은 $90.8 \%( \pm 4.4)$ 로 비교적 높은 편이나
각 문항별로 살펴봤을 때 응답률이 $100 \%$ 인 문항은 없었다 (Appendix 2). 이는 설문지에 참여한 환자들의 $62 \%$ 가 고도 또는 심도 난청이었을 뿐만 아니라 $55 \%$ 가 70 대 이상의 고령으 로(Table 1) 대상자 군이 집중력 및 인지기능이 다소 저하된 집 단으로 편향되었음을 확인할 수 있었고, 이로 인해 응답률이 저하된 것으로 판단된다.

K-APHAB의 Cronbach's alpha 값은 0.8로 높은 내적 일치 도 및 신뢰도를 보여주었다. 세부 항목의 Cronbach's alpha 값을 살펴보면 $\mathrm{EC}$ 와 $\mathrm{AV}$ 의 경우 각각 $0.86,0.85$ 로 높았으나, $\mathrm{BN}$ 및 RV에서는 0.58과 0.65 로 다소 낮은 값을 보였다. Cox 와 Alexander ${ }^{7)}$ 는 이전 논문에서 해당 논문의 환자군과 다른 환자군에서는 내적 신뢰도가 감소될 수 있다고 예상하였으 며, $\mathrm{APHAB}$ 의 중국어 번역본에서도 $\mathrm{AV}$ 의 경우 Cronbach's alpha 값이 0.50 으로 낮게 나온 바 있다..$^{14}$

$\mathrm{K}-\mathrm{APHAB}$ 의 요인 분석에서는 24 개의 항목을 $\mathrm{Cox}^{7,13)}$ 가 제시한 4 개의 요인으로 추출하는 데에는 실패하였다. 1 이상 의 eigenvalue를 갖는 총 5 개의 요인이 추출되었으나, scree plot에서 3번째 요인 이후로 기울기가 급격히 줄어드는 것을 확인하고 요인 수를 3 개로 결정하였다. 비록 원저와 같이 4 개 의 요인으로 추출하는 데에는 실패하였지만, $\mathrm{APHAB}$ 와 K$\mathrm{APHAB}$ 의 하부요인에 따른 문항들을 비교하였을 때 서로 유사한 형태로 묶여짐을 확인할 수 있었다. $30 \%$ 로 가장 설명 력이 높았던 K-APHAB의 제 1 요인은 $\mathrm{APHAB}$ 의 $\mathrm{EC} 6$ 문항과 $\mathrm{BN} 3$ 문항, RV 3 문항으로 이루어져 있었고, 이는 조용한 환경 에서의 대화를 위주로 하되 소음 및 반향음 환경의 대화가 일 부 섞인 일상 생활 전반에 관련된 내용을 다루고 있어 '일상 생활에서의 의사 소통'이라고 명명하였다. $21 \%$ 의 설명력을 가진 제2요인은 $\mathrm{APHAB}$ 의 $\mathrm{AV}$ 6문항으로만 이루어져 있었 고, 모두 큰 소리에 대한 불쾌감에 관련되어 있어 '큰 소리에 대한 불쾌감'이라 명명하였다. $7 \%$ 의 설명력을 가진 제 3요인은 $\mathrm{APHAB}$ 의 BN 3 문항, RV 3 문항으로 구성되었고, 주로 소음 환경 또는 반향음에서의 의사 소통에 관련된 내용이므로 '소 음/반향음에서의 의사 소통'이라 명명하였다.

준거 타당도 검증을 위해 보청기 착용 전후 순음청력검사 의 역치와 K-APHAB 점수 사이의 상관관계를 평가하였지만 통계적으로 유의하지 않았다. 일반적으로 보청기의 만족도는 중도나 중고도 난청에서 가장 높으며, 경도나 고도 난청에서 는 비교적 낮다고 알려져 있으나, 이번 K-APHAB 설문에 참 여한 환자들의 약 $62 \%$ 가 고도 난청 이상의 환자들이었으며, 이로 인해 선형적 상관관계를 나타내기 어려웠을 것으로 추 정된다. 하지만 각 문항별 보청기 착용 전과 착용 후의 $\mathrm{K}-$ $\mathrm{APHAB}$ score는 모든 문항에서 통계적으로 유의한 차이를 보였고, 이를 통해 $\mathrm{K}-\mathrm{APHAB}$ 의 준거 타당도가 검증되었다 
고 볼 수 있겠다.

저자들은 $\mathrm{APHAB}$ 를 한국어로 번역하였으며, 한국어판 $\mathrm{APHAB}$ 의 타당도 및 신뢰도를 증명하였다. 이 과정을 통하 여 국내 보청기 사용 난청환자들의 보청기 착용 이득 평가에 표준화된 한국어판 $\mathrm{APHAB}$ 를 제공할 수 있게 되었다. 또한 표준화된 설문지를 사용함으로써 $\mathrm{APHAB}$ 를 이용한 연구들 의 비교 분석이 가능하게 될 것으로 기대한다.

\section{Acknowledgments}

This study received the approval (Research Grant No. 1409-092610) from the Institutional Review Board of Seoul National University Hospital.

\section{REFERENCES}

1) Yun DH, Yoon $T H$, Lee KS. Subjective satisfaction in hearing aid users by APHAB. Korean J Otolaryngol-Head Neck Surg 2000;43 (7):698-702.

2) Lee IY, Byun JY, Kim H, Chang MK, Cho JS, Cha CI. The application of the satisfaction with amplification in daily life scale in hearing aid users. Korean J Otolaryngol-Head Neck Surg 2004;47(12):1217-23.

3) Chu H, Cho YS, Park SN, Byun JY, Shin JE, Han GC, et al. Standardization for a Korean adaptation of the international outcome inventory for hearing aids: study of validity and reliability. Korean J Otorhinolaryngol-Head Neck Surg 2012;55(1):20-5.
4) Tannahill JC. The hearing handicap scale as a measure of hearing aid benefit. J Speech Hear Disord 1979;44(1):91-9.

5) Walden BE, Demorest ME, Hepler EL. Self-report approach to assessing benefit derived from amplification. J Speech Hear Res 1984;27(1): $49-56$.

6) Newman CW, Weinstein BE. The hearing handicap inventory for the elderly as a measure of hearing aid benefit. Ear Hear 1988;9(2):81-5.

7) Cox RM, Alexander GC. The abbreviated profile of hearing aid benefit. Ear Hear 1995;16(2):176-86.

8) Cox RM, Alexander GC. The international outcome inventory for hearing aids (IOI-HA): psychometric properties of the English version. Int J Audiol 2002;41(1):30-5.

9) Cox RM, Alexander GC. Measuring satisfaction with amplification in daily life: the SADL scale. Ear Hear 1999;20(4):306-20.

10) Kochkin $S$. The efficacy of hearing aids in achieving compensation equity in the workplace. Hear J 2010;63(10):19-28.

11) Cox RM, Gilmore C. Development of the profile of hearing aid performance (PHAP). J Speech Hear Res 1990;33(2):343-57.

12) Cox RM, Gilmore C, Alexander GC. Comparison of two questionnaires for patient-assessed hearing aid benefit. J Am Acad Audiol 1991; 2(3):134-45.

13) Cox RM. Administration and application of the APHAB. Hear J 1997; 50(4):32-48.

14) Kam AC, Tong MC, van Hasselt A. Cross-cultural adaptation and validation of the Chinese abbreviated profile of hearing aid benefit. Int J Audiol 2011;50(5):334-9.

15) Kochkin S. Subjective measures of satisfaction and benefit: establishing norms. Semin Hear 1997;18(1):37-48. 


\section{APPENDIX}

\section{Appendix 1. Korean Version of Abbreviated Profile of Hearing Aid Benefit}

설명: 귀하의 일상 경험과 가장 가까운 대답에 동그라미를 하십시오. 각
각의 보기는 빈도를 표시합니다. 빈도를 보고 대답을 결정하십시오. 예
를 들어, 귀하의 경험이 약 $75 \%$ 문항에 해당하면 '다'에 동그라미를 하
십시오. 만약 문항에서 설명한 상황을 경험한 적이 없다면 귀하가 경험
해 본 유사한 상황을 생각해 보고 그 상황에 맞게 대답하십시오. 모르
는 내용은 빈칸으로 남겨두십시오.

설명: 귀하의 일상 경험과 가장 가까운 대답에 동그라미를 하십시오. 각 각의 보기는 빈도를 표시함니다. 빈도를 보고 대담을 결정하십시오. 예 를 들어, 귀하의 경힘이 약 $75 \%$ 문항에 해당하면 다에 동그라미를 하 십시오. 만약 문항에서 설명한 상황을 경험한 적이 없다면 귀하가 경험 는 내용은 빈칸으로 남겨두십시오.
가. 항상 $(99 \%)$
나. 거의 항상 $(87 \%)$
다. 대체로 $(75 \%)$
라. 절반 정도 $(50 \%)$
마. 가끔(25\%)
바. 드물게 $(12 \%)$
사. 전혀 아니다(1\%)

\begin{tabular}{|c|c|c|c|}
\hline & & 보청기 미사용 시 & 보청기 사용 시 \\
\hline 1. & 나는 혼잡한 식품 매장에서 계산을 할 때 잘 알아들을 수 있습니다. & 가 나다라마바 사 & 가 나다라 마바사 \\
\hline 2. & 나는 강의나 수업을 들을 때 많은 내용을 놓칩니다. & 가 나다라마바사 & 가나다라마바사 \\
\hline 3. & 화재 경보기나 또는 자명종과 같은 갑작스러운 소리가 불쾌합니다. & 가 나다라 마바 사 & 가 나다라 마바사 \\
\hline 4. & 나는 집에서 가족 중 한 명과 대화할 때 어려움이 있습니다. & 가 나다라마바사 & 가 나다라 마바 사 \\
\hline 5. & 나는 영화관이나 공연장에서 대사를 이해하는 데 어려움이 있습니다. & 가 나다라마바 사 & 가 나다라 마 바 사 \\
\hline 6. & $\begin{array}{l}\text { 나는 차 안에서 뉴스를 들을 때 식구들이 말을 하면, 라디오의 } \\
\text { 뉴스를 듣기가 어렵습니다. }\end{array}$ & 가 나다라마바사 & 가 나다라 마바 사 \\
\hline 7. & $\begin{array}{l}\text { 나는 여러 사람과의 저녁식사 중 한 사람과 이야기를 할 때 } \\
\text { 어려움이 있습니다. }\end{array}$ & 가 나다라 마바사 & 가나다라 마바사 \\
\hline 8. & 거리의 교통 소음이 너무 시끄럽습니다. & 가 나다라마바사 & 가 나다라마바사 \\
\hline 9. & $\begin{array}{l}\text { 나는 커다란 빈 방안에서 건너편 누군가와 이야기를 할 때 그 말을 } \\
\text { 이해할 수 있습니다. }\end{array}$ & 가 나다라마바사 & 가나다라마바사 \\
\hline 10. & $\begin{array}{l}\text { 나는 작은 사무실 안에서 면접을 보거나 질문에 대답할 때 대화를 } \\
\text { 이해하는 것이 어렵습니다. }\end{array}$ & 가 나다라마바사 & 가나다라 마바사 \\
\hline 11. & $\begin{array}{l}\text { 나는 극장에서 영화나 연극을 볼 때 주변에서 속삭이거나 } \\
\text { 바스락거리는 소리가 나도 대사를 이해할 수 있습니다. }\end{array}$ & 가나다라 마바 사 & 가 나다라마바 사 \\
\hline 12. & 나는 친구와 조용히 이야기를 할 때 알아듣기가 어렵습니다. & 가 나다라마바사 & 가 나다라 마바 사 \\
\hline 13. & $\begin{array}{l}\text { 샤워기 또는 변기의 물을 내릴 때 나는 소리는 불쾌하게 } \\
\text { 시끄럽습니다. }\end{array}$ & 가나다라 마바사 & 가나다라마바사 \\
\hline 14. & $\begin{array}{l}\text { 누군가 작은 모임에서 말을 하고 청중이 조용히 듣고 있을 때에도 } \\
\text { 나는 내용을 알아들으려면 애써야 합니다. }\end{array}$ & 가 나다라마바사 & 가 나다 라 마 바 사 \\
\hline 15. & $\begin{array}{l}\text { 나는 진찰실에서 담당 의사와 조용히 대화할 때 알아듣기가 } \\
\text { 어렵습니다. }\end{array}$ & 가 나다라마바사 & 가 나다라 마바 사 \\
\hline 16. & $\begin{array}{l}\text { 나는 여러 사람이 이야기를 하고 있을 때에도 그 대화들을 } \\
\text { 알아들을 수 있습니다. }\end{array}$ & 가 나 다라 마 바 사 & 가 나 다 라 마 바 사 \\
\hline 17. & 공사장의 소음은 불쾌하게 시끄럽습니다. & 가 나다라 마바사 & 가나다라 마 바 사 \\
\hline 18. & 나는 강의 또는 예배에서 하는 말을 알아듣기 어렵습니다. & 가 나다라 마바 사 & 가 나다라 마 바 사 \\
\hline 19. & 나는 군중 속에 있을 때 다른 사람들과 대화를 나눌 수 있습니다. & 가 나다라마바 사 & 가 나다라마바사 \\
\hline & $\begin{array}{l}\text { 가까이에서 소방차 사이렌 소리가 나면 너무 시끄러워서 귀를 } \\
\text { 막아야 합니다. }\end{array}$ & 가나다라 마바 사 & 가 나 다 라 마 바 사 \\
\hline
\end{tabular}


21. 나는 종교의식에서 설교나 강의를 이해할 수 있습니다.

22. 급정거할 때 나는 타이어 소리는 불쾌하게 시끄럽습니다.

23. 나는 조용한 방에서 일대일로 대화를 나눌 때 사람들에게 다시 말해달라고 부탁해야 합니다.

24. 나는 에어컨이나 환풍기가 켜져 있을 때 다른 사람들의 대화를 알아듣기가 어렵습니다.
가 나다라 마 바 사

가 나다라 마 바사

가 나다 라 마바 사

가 나다 라 마 바사

가 나다라마바사

가 나 다 라 마바 사

가 나다라 마바사

가 나 다 라 마 바사 
Appendix 2. Response Rate, K-APHAB Score, Mean of Hearing Aid Benefit of Each Item of the K-APHAB

\begin{tabular}{|c|c|c|c|c|c|c|c|}
\hline \multirow{2}{*}{ Subscale } & \multirow{2}{*}{ Item } & \multirow{2}{*}{$\begin{array}{l}\text { Response } \\
\text { rate }(\%)\end{array}$} & \multicolumn{2}{|c|}{ K-APHAB score } & \multirow{2}{*}{$p$-value } & \multirow{2}{*}{$\begin{array}{c}\text { Mean of hearing } \\
\text { aid benefit }\end{array}$} & \multirow{2}{*}{$\mathrm{SD}$} \\
\hline & & & Without hearing aid & With hearing aid & & & \\
\hline $\mathrm{BN}$ & $1^{*}$ & 92 & 40.5 & 62.8 & $<0.000$ & 22.3 & 42.0 \\
\hline RV & 2 & 84 & 56.0 & 39.0 & $<0.000$ & 17.0 & 42.6 \\
\hline AV & 3 & 95 & 31.0 & 47.9 & $<0.000$ & -16.9 & 38.5 \\
\hline $\mathrm{EC}$ & 4 & 95 & 48.1 & 30.2 & $<0.000$ & 17.9 & 41.2 \\
\hline RV & 5 & 83 & 58.8 & 34.8 & $<0.000$ & 24.0 & 37.6 \\
\hline $\mathrm{BN}$ & 6 & 91 & 64.6 & 39.3 & $<0.000$ & 25.3 & 37.9 \\
\hline $\mathrm{BN}$ & 7 & 96 & 58.6 & 34.6 & $<0.000$ & 24.0 & 36.1 \\
\hline AV & 8 & 95 & 23.8 & 45.8 & $<0.000$ & -22.0 & 38.0 \\
\hline RV & $9^{*}$ & 94 & 36.4 & 57.6 & $<0.000$ & 21.2 & 38.1 \\
\hline $\mathrm{EC}$ & 10 & 88 & 52.5 & 34.5 & $<0.000$ & 18.0 & 41.8 \\
\hline RV & $11^{*}$ & 87 & 31.4 & 55.6 & $<0.000$ & 24.1 & 35.0 \\
\hline $\mathrm{EC}$ & 12 & 94 & 56.0 & 29.8 & $<0.000$ & 26.2 & 38.6 \\
\hline AV & 13 & 96 & 17.0 & 33.4 & $<0.000$ & -16.4 & 32.1 \\
\hline $\mathrm{EC}$ & 14 & 93 & 69.9 & 43.0 & $<0.000$ & 26.9 & 34.4 \\
\hline $\mathrm{EC}$ & 15 & 95 & 61.5 & 33.0 & $<0.000$ & 28.5 & 39.9 \\
\hline $\mathrm{BN}$ & $16^{*}$ & 91 & 35.8 & 53.4 & $<0.000$ & 17.6 & 38.3 \\
\hline AV & 17 & 93 & 31.6 & 49.9 & $<0.000$ & -18.3 & 35.3 \\
\hline $\mathrm{RV}$ & 18 & 82 & 63.1 & 36.9 & $<0.000$ & 26.2 & 38.3 \\
\hline $\mathrm{BN}$ & $19 *$ & 88 & 30.7 & 52.2 & $<0.000$ & 21.5 & 38.1 \\
\hline AV & 20 & 93 & 25.2 & 43.4 & $<0.000$ & -18.2 & 35.0 \\
\hline $\mathrm{RV}$ & $21^{*}$ & 84 & 33.2 & 60.7 & $<0.000$ & 27.5 & 37.8 \\
\hline AV & 22 & 86 & 26.7 & 44.0 & $<0.000$ & -17.3 & 36.0 \\
\hline $\mathrm{EC}$ & 23 & 93 & 60.8 & 29.5 & $<0.000$ & 31.3 & 35.4 \\
\hline $\mathrm{BN}$ & 24 & 92 & 58.7 & 35.1 & $<0.000$ & 23.6 & 37.1 \\
\hline
\end{tabular}

*reversed items. Hearing aid benefit: computed by subtracting the results for "with hearing aid" from those for "without hearing aid", Hearing aid benefit of reversed items: computed by subtracting the results for "without hearing aid" from those for "with hearing aid". K-APHAB: Korean version of abbreviated profile of hearing aid benefit, EC: ease of communication, BN: background noise, RV: reverberation, AV: aversiveness, SD: standard deviation 
Appendix 3. Results of the Principal Component Factor Analysis of the K-APHAB

\begin{tabular}{|c|c|c|c|c|}
\hline \multirow{2}{*}{ Subscale } & \multirow{2}{*}{ Item } & \multicolumn{3}{|c|}{ Factor } \\
\hline & & 1 & 2 & 3 \\
\hline $\mathrm{BN}$ & 1 & -0.19 & 0.14 & 0.70 \\
\hline RV & 2 & 0.67 & -0.06 & -0.12 \\
\hline AV & 3 & 0.24 & 0.55 & -0.35 \\
\hline $\mathrm{EC}$ & 4 & 0.79 & -0.07 & -0.04 \\
\hline RV & 5 & 0.84 & -0.03 & -0.10 \\
\hline $\mathrm{BN}$ & 6 & 0.80 & 0.03 & -0.12 \\
\hline $\mathrm{BN}$ & 7 & 0.83 & -0.08 & 0.01 \\
\hline AV & 8 & 0.11 & 0.74 & -0.22 \\
\hline RV & 9 & 0.21 & -0.24 & 0.60 \\
\hline $\mathrm{EC}$ & 10 & 0.56 & -0.28 & -0.02 \\
\hline RV & 11 & 0.08 & -0.17 & 0.70 \\
\hline $\mathrm{EC}$ & 12 & 0.74 & 0.04 & 0.01 \\
\hline AV & 13 & -0.003 & 0.71 & -0.04 \\
\hline $\mathrm{EC}$ & 14 & 0.78 & 0.03 & 0.24 \\
\hline $\mathrm{EC}$ & 15 & 0.76 & 0.06 & 0.03 \\
\hline $\mathrm{BN}$ & 16 & 0.13 & -0.26 & 0.58 \\
\hline AV & 17 & -0.23 & 0.73 & -0.23 \\
\hline RV & 18 & 0.64 & 0.24 & 0.27 \\
\hline $\mathrm{BN}$ & 19 & 0.04 & -0.25 & 0.62 \\
\hline AV & 20 & 0.02 & 0.79 & -0.20 \\
\hline RV & 21 & 0.15 & -0.36 & 0.57 \\
\hline AV & 22 & 0.05 & 0.81 & -0.35 \\
\hline $\mathrm{EC}$ & 23 & 0.79 & -0.03 & 0.12 \\
\hline $\mathrm{BN}$ & 24 & 0.73 & 0.02 & 0.27 \\
\hline
\end{tabular}

K-APHAB: Korean version of abbreviated profile of hearing aid benefit, EC: ease of communication, BN: background noise, RV: reverberation, AV: aversiveness 